\title{
Emergence of the Phosphoinositide 3-Kinase-Akt- Mammalian Target of Rapamycin Axis in Transforming Growth Factor- $\beta$-Induced Epithelial-Mesenchymal Transition
}

\author{
Samy Lamouille Rik Derynck \\ Departments of Cell and Tissue Biology, and Anatomy, Programs in Cell Biology and Developmental Biology, \\ University of California, San Francisco, Calif., USA
}

\section{Key Words}

Cell invasion • Epithelial-mesenchymal transition •

Metastasis $\cdot$ Smad signaling

\begin{abstract}
During development and in pathological contexts such as fibrosis and cancer progression, epithelial cells can initiate a complex transcriptional reprogramming, accompanied by dramatic morphological changes, in a process named 'epithelial-mesenchymal transition' (EMT). In this transition, epithelial cells lose their epithelial characteristics to acquire mesenchymal properties and increased motile and invasive behavior.Transforming growth factor- $\beta$ (TGF- $\beta$ ) has emerged as a major inducer of EMT through activation of downstream signaling pathways, including Smad and non-Smad signaling pathways. Among the non-Smad pathways, increasing evidence is emerging that the phosphoinositide 3-kinaseAkt-mammalian target of rapamycin axis plays a major role in TGF- $\beta$-induced EMT, notably through the regulation of translation and cell invasion. Pharmacological inhibitors of the phosphoinositide 3-kinase-Akt-mammalian target of rapamycin pathway may therefore represent an opportunity to selectively target essential aspects of TGF- $\beta$-induced EMT and provide an approach to prevent cancer cell dissemination toward metastasis, without the need to fully inactivate TGF- $\beta$ signaling.

Copyright $\odot 2010$ S. Karger AG, Basel
\end{abstract}

\section{Definition of Epithelial-Mesenchymal Transition}

During development, in response to injury, inflammation and pathological conditions, epithelial cells show a remarkable differentiation plasticity. A manifestation of this plasticity is the process that has been named 'epithelial to mesenchymal transformation' or 'transdifferentiation', but is now more commonly referred to as 'epithelialmesenchymal transition' (EMT). In EMT, the loss of epithelial characteristics, such as intercellular contacts and cell polarity, is complemented by the acquisition of mesenchymal characteristics and increased cell motility and invasion (fig. 1). This transition involves a complex transcriptional reprogramming and non-transcriptional signaling events that contribute to major changes in cell morphology and behavior. Depending on the physiological and tissue contexts, cells that have undergone EMT can revert to reacquire their epithelial characteristics, thus leading to a mesenchymal-epithelial transition [Kalluri and Weinberg, 2009]. Over the last 15 years, transforming growth factor- $\beta$ (TGF- $\beta$ ) has been shown to function as a potent inducer of EMT, with its signaling pathways intimately involved in the activation and progression of EMT [Moustakas and Heldin, 2007; Miyazono, 2009; Xu et al., 2009].

\section{KARGER}

두 2010 S. Karger AG, Basel

Fax +41613061234 E-Mail karger@karger.ch www.karger.com
Dr. Rik Derynck

Department of Cell and Tissue Biology, University of California at San Francisco

513 Parnassus Avenue, Room HSW-613

San Francisco, CA 94143-0512 (USA)

Tel. +1 415476 7322, Fax +1 415502 7338, E-Mail rik.derynck@ ucsf.edu 


\begin{tabular}{|c|c|c|c|}
\hline \multicolumn{4}{|c|}{ Abbreviations used in this paper } \\
\hline ATF3 & activating transcription factor 3 & PDK1 & 3-phosphoinositide-dependent kinase 1 \\
\hline bHLH & basic helix-loop-helix & $\mathrm{PI} 3$ & phosphoinositide 3 \\
\hline CAR & coxsackie and adenovirus receptor & PIP3 & phosphatidylinositol $(3,4,5)$-triphosphate \\
\hline $4 \mathrm{E}-\mathrm{BP} 1$ & eIF4E-binding protein & Protor & protein observed with Rictor \\
\hline eIF4E & eukaryotic translation initiation factor $4 \mathrm{E}$ & PTEN & phosphatase and tensin homolog \\
\hline EMT & epithelial-mesenchymal transition & Raptor & regulatory associated protein of mammalian target \\
\hline Erk & extracellular-regulated kinase & & of rapamycin \\
\hline Grb2 & growth factor receptor-bound protein 2 & Rheb & ras homolog enriched in brain \\
\hline GSK-3 $\beta$ & glycogen synthase kinase- $3 \beta$ & Rictor & rapamycin-insensitive companion of mammalian \\
\hline HMGA2 & high-mobility group A2 & & target of rapamycin \\
\hline Id & inhibitor of DNA binding & ROCK & rho-associated coiled-coil containing protein kinase \\
\hline JNK & c-Jun N-terminal kinase & ShcA & src homology 2 domain containing transforming \\
\hline MAP & mitogen-activated protein & & protein A \\
\hline MEK & mitogen-activated protein kinase/Erk kinase & Sos & son of sevenless \\
\hline mLST8 & mammalian lethal with SEC13 protein 8 & TAK1 & transforming growth factor- $\beta$-activated kinase 1 \\
\hline $\mathrm{mSin} 1$ & mammalian stress-activated protein & TGF- $\beta$ & transforming growth factor- $\beta$ \\
\hline & kinase-interacting protein 1 & TRAF6 & tumor necrosis factor receptor-associated factor 6 \\
\hline mTOR & mammalian target of rapamycin & TSC & tuberous sclerosis complex \\
\hline mTORC1 & mammalian target of rapamycin complex 1 & $\mathrm{~T} \beta \mathrm{RI}$ & transforming growth factor- $\beta$ type I receptor \\
\hline mTORC2 & mammalian target of rapamycin complex 2 & T $\beta$ RII & transforming growth factor- $\beta$ type II receptor \\
\hline NMuMG & normal murine mammary gland cell & ZEB & zinc finger E-box binding homeobox \\
\hline
\end{tabular}

Three types of EMT with distinct functional consequences have been distinguished, depending on the developmental and physiological context [Kalluri and Weinberg, 2009]. Type 1 EMT is linked to developmental processes. During vertebrate embryonic development, EMT occurs in a precise and programmed spatiotemporal manner, starting as early as gastrulation, when it mediates the formation of the mesoderm. EMT is also a key process in the delamination of neural crest cells that disperse to give rise to a variety of cell types, including osteoblasts, chondrocytes and muscle cells. At later stages, an EMT-like process allows endothelial cells to transition into mesenchymal cells, e.g. in heart development. EMT is also involved in the fusion of the palatal shelves and in Müllerian duct regression [Acloque et al., 2009; Thiery et al., 2009]. The 2 other types of EMT are not involved in normal development, but occur in response to injury or inflammation and are at the basis of pathological processes. Type 2 EMT occurs in wound healing, tissue repair and regeneration and is also associated with inflammation-induced fibrosis. Such fibrosis involves a mesenchymal conversion of epithelial cells in addition to an infiltration and proliferation of fibroblasts [Iwano et al., 2002; Kalluri and Neilson, 2003]. Finally, during tumor progression, carcinoma cells can escape the environment of the primary tumor by initiating an EMT process, resulting in motility and invasive behavior which poten- tially leads to metastasis at distant sites. Once in the new loci, these cancer cells can then revert through mesenchymal-epithelial transition to form metastatic carcinomas. The EMT associated with cancer invasion and progression has been classified as type 3 EMT [Thiery and Sleeman, 2006; Kalluri and Weinberg, 2009; Klymkowsky and Savagner, 2009].

\section{Molecular Events during EMT}

The transition from an epithelial to a mesenchymal phenotype involves dramatic changes in gene expression, as well as in cell morphology and behavior (fig. 1). An early step in EMT is the dissolution of epithelial cell junction complexes that mediate cell-cell adhesion. These specialized junction complexes consist of transmembrane molecules that, through interactions with adaptor proteins beneath the plasma membrane, interact with the actin cytoskeleton, intermediate filaments or microtubules. Among these complexes, tight junctions contain occludin and claudins that bind zonula occludens proteins, adherens junctions are characterized by E-cadherin that binds to $\beta$ - or p120-catenin, gap junctions contain connexins, and desmosomes consist of desmosal cadherins that bind proteins in the submembranous plaque. The rapid delocalization of these junctional pro- 


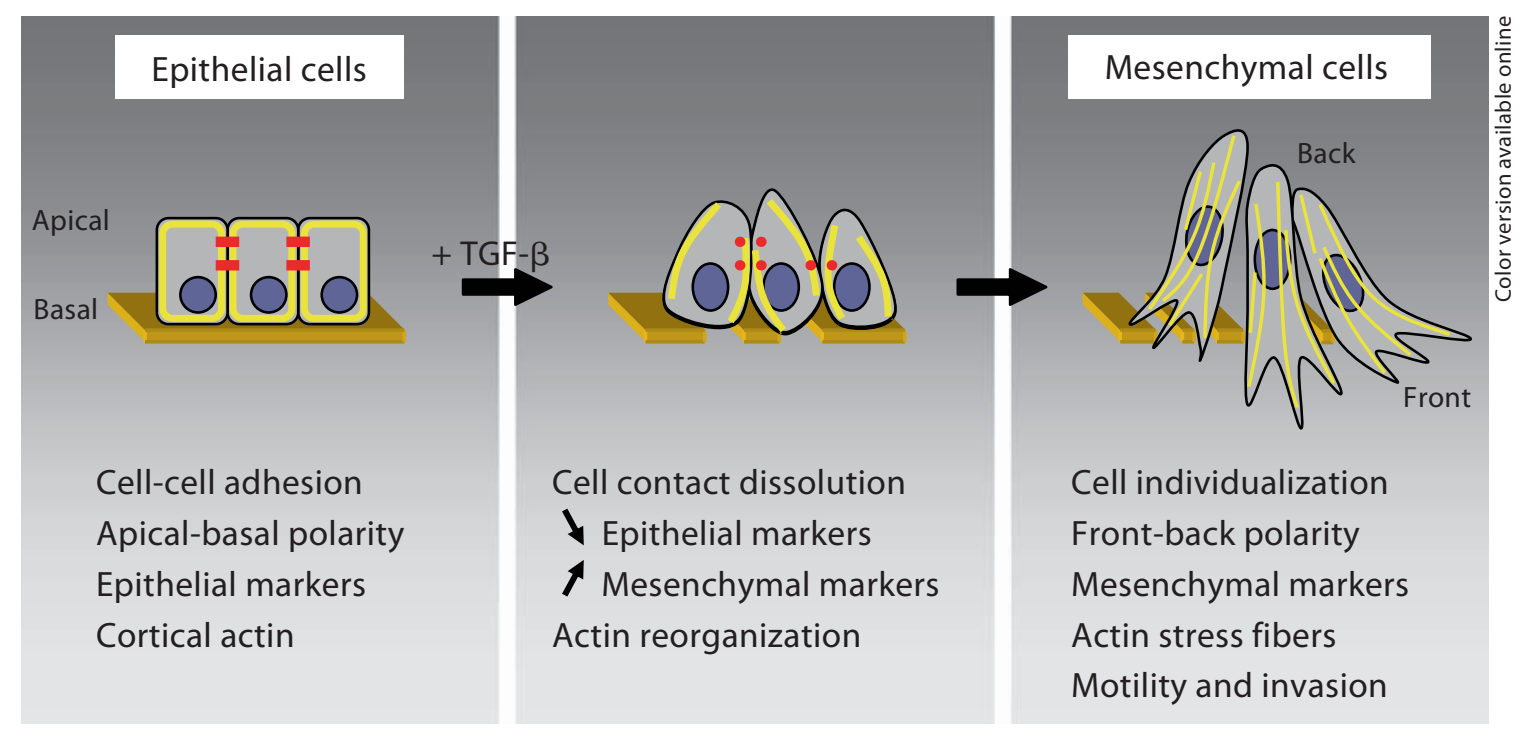

Fig. 1. TGF- $\beta$-induced EMT. Disassembly of epithelial cell-cell contacts (red in the online version) and loss of cell polarity are the first steps in TGF- $\beta$-induced EMT. The expression of epithelial marker genes is repressed concomitantly with increased expression of mesenchymal markers. In addition, cortical actin (yellow in the online version) reorganizes into stress fibers. TGF- $\beta$-induced EMT is accompanied by increased motility and invasive behavior, in part mediated by the expression of metalloproteinases and matrix protein turnover.

teins and the downregulation of their expression represent early steps in EMT that lead to the individualization of the cells [Thiery and Sleeman, 2006; Xu et al., 2009]. Concomitantly, the cells lose their apical-basal polarity and epithelial cell architecture. Two polarity complexes, one composed of Par3 and Par6, and the other one comprising Crumbs-3, localize predominantly to tight junctions and are disrupted when the tight junctions are disassembled [Moreno-Bueno et al., 2008]. Accompanying the disassembly of the junction complexes, the cortical actin cytoskeleton is reorganized through the activities of Rho-like GTPases (Rho, Rac and Cdc42) into stress fibers extending within lamellipodia and filopodia. In these stress fiber-enriched protrusions, actin can dynamically polymerize and depolymerize allowing for enhanced cell motility [Zavadil and Böttinger, 2005; Yilmaz and Christofori, 2009].

Since many of the junction complex proteins characterize epithelial cells, the dissolution of the junctions results in a loss of many epithelial marker proteins. Among them, decrease in E-cadherin expression has become a major indication of loss of epithelial characteristics. Further, the expression of other epithelial proteins, such as epithelial-specific cytokeratins, is also downregulated. In EMT, the loss of epithelial markers is accompanied by an induction of the expression of mesenchymal proteins, such as vimentin. In addition, expression of $\mathrm{N}$-cadherin, a mesenchymal protein that promotes migration and invasion, increases while the expression of E-cadherin decreases. EMT is also marked by increased expression of matrix metalloproteinases, which degrade extracellular matrix, and extracellular matrix proteins such as fibronectin, collagens or laminin [Zavadil and Böttinger, 2005; Zeisberg and Neilson, 2009]. Together, loss of epithelial protein expression, changes in cell shape and expression of mesenchymal proteins result in a motile cell behavior that allows invasion into surrounding tissues with increased extracellular matrix turnover.

The complex changes in gene expression that are at the basis of EMT result largely from the actions of 3 families of transcription factors, i.e. the Snail, ZEB and basic helixloop-helix (bHLH) families, whose expression and activities are induced upon initiation of EMT [Peinado et al., 2007]. The Snail (Snail1, Snail2 and Snail3) and ZEB (ZEB1 and ZEB2) proteins represent 2 classes of zinc finger transcription factors whose expression increases during EMT and which bind E-box elements in regulatory promoter sequences. Snaill and Snail2 can recruit corepressors such as histone deacetylases or C-terminal binding proteins, and in this way transcriptionally repress the expression of target genes, such as the gene encoding Ecadherin [Batlle et al., 2000; Cano et al., 2000; Barrallo- 
Gimeno and Nieto, 2005]. Similarly, the ZEB transcription factors also have the ability to recruit corepressors, such as C-terminal binding protein, and repress E-cadherin transcription [Comijn et al., 2001; Eger et al., 2005]. Together, Snail and ZEB proteins repress the expression of a number of genes encoding tight junction, adherens junction, desmosome and polarity complex proteins. Besides repressing the expression of epithelial markers, these transcription factors also participate in the increased expression of proteins that characterize the mesenchymal phenotype, such as fibronectin, vitronectin, collagen, $\mathrm{N}$ cadherin and matrix metalloproteinases [Peinado et al., 2007]. bHLH transcription factors also play a role in the progression of EMT. Among these, Twist 1 and Twist 2 dimerize with another type of bHLH proteins, i.e. E-proteins. These heterodimers then bind to DNA and repress the expression of some epithelial genes such as the gene encoding E-cadherin, while activating the expression of some mesenchymal genes [Perez-Moreno et al., 2001; Yang et al., 2004]. Since inhibitor of DNA binding (Id) proteins inhibit the dimerization and function of Twist transcription factors through dominant negative interference, induction of EMT is accompanied by downregulation of Id protein expression [Ruzinova and Benezra, 2003; Perk et al., 2005]. Interestingly, Snail proteins orchestrate the induction of EMT by increasing the expression of ZEB and bHLH factors [Peinado et al., 2007]. A further level of control in the regulation of this transcription network is exerted by microRNAs. Indeed, members of the miR-200 family act as essential regulators of EMT. They were shown to target and repress the expression of ZEB1 and ZEB2, and, accordingly, their expression is downregulated in cells that undergo EMT, thus leading to a decrease in E-cadherin expression [Gregory et al., 2008].

Recent insights have revealed that signaling pathways, including those initiated by TGF- $\beta$, regulate the expression and activities of these transcription factors [Moustakas and Heldin, 2007; Xu et al., 2009]. The orchestration of these transcription pathways, in combination with non-transcription signaling responses, allows TGF- $\beta$ to act as a potent inducer of EMT. Dissecting the mechanisms of the EMT response to TGF- $\beta$ provides a paradigm for the cellular basis of epithelial plasticity.

\section{TGF- $\beta$, a Major Inducer of EMT}

A variety of studies have implicated TGF- $\beta$ as an inducer or essential mediator of EMT in embryonic development, fibrosis and tumorigenesis. For example, during cardiac development, TGF- $\beta_{1}$ and TGF- $\beta_{2}$ are expressed in the atrioventricular canal and outflow tract tissue at the onset of EMT, permitting the formation of the heart valves [Nakajima et al., 2000]. TGF- $\beta_{2}$ null mice present severe cardiac defects with abnormalities in these regions, and inhibition of TGF- $\beta_{2}$ blocks EMT in mouse heart explant cultures [Azhar et al., 2003; Mercado-Pimentel and Runyan, 2007]. As another example, TGF- $\beta_{3}$ expression is essential for palatal development and fusion. It is expressed at the site and time of fusion of the palatal shelves, when the epithelial cells undergo EMT, and targeted inactivation of the gene encoding TGF- $\beta_{3}$ results in a cleft palate that correlates with the absence of EMT [Pelton et al., 1990; Nawshad et al., 2004].

Consistent with its ability to induce a strong fibrotic response when injected subcutaneously, TGF- $\beta$ acts as a mediator of pathological fibrosis in a variety of tissues including the kidney, liver, lung and heart. While this response involves the attraction and proliferation of fibroblasts in response to TGF- $\beta$, increasing evidence is emerging that TGF- $\beta$ is also involved in EMT leading to fibrosis. Accordingly, in mouse models and human patients, TGF- $\beta_{1}$ expression is increased in chronic kidney disease prior to fibrosis [Schnaper et al., 2003]. Patients with liver disease progressing to hepatic fibrosis also show increased TGF- $\beta_{1}$ expression in biliary epithelial cells, and increased TGF- $\beta_{1}$ expression occurs in a mouse model of induced liver fibrosis, while blocking TGF- $\beta_{1}$ signaling demonstrated significant antifibrotic effect in the liver [Gressner et al., 2002; Meindl-Beinker and Dooley, 2008]. Fibroblasts isolated from patients with pulmonary fibrosis show increased secretion of TGF- $\beta$ resulting in hyperactive TGF- $\beta$ signaling [Willis and Borok, 2007]. Further, lineage-tracing experiments in mouse models illustrate a role of EMT of alveolar epithelial cells in lung fibrosis. In the adult heart, an endothelial to mesenchymal transition process occurs in cardiac fibrosis. This process is controlled by TGF- $\beta$, and progression of cardiac fibrosis is inhibited in transgenic mice with impaired TGF- $\beta$ signaling [Zeisberg et al., 2007]. These in vivo observations are complemented by cell culture experiments showing that TGF- $\beta$ induces EMT in renal tubular epithelial cells, hepatic stellate cells and alveolar epithelial cells, as well as initiating endothelial to mesenchymal transition in endothelial cells [Gressner et al., 2002; Zeisberg et al., 2003; Willis and Borok, 2007; Zeisberg et al., 2007].

TGF- $\beta$-induced EMT may also play an important role in carcinoma progression. EMT is thought to be a prerequisite for the invasive behavior of carcinoma cells, leading 
to dissemination and metastasis [Thiery, 2003; Thiery and Sleeman, 2006; Kalluri and Weinberg, 2009]. Such a role for TGF- $\beta$ is consistent with the increased production and activation of TGF- $\beta$ by cancer cells and has been well validated by cell culture and mouse model studies [Bierie and Moses, 2006a]. In addition, in vivo studies confirmed a correlation between the conversion of squamous into more invasive spindle cell carcinomas and the expression of activated TGF- $\beta_{1}$ [Cui et al., 1996; Portella et al., 1998; Akhurst, 2008]. Moreover, the increase in TGF- $\beta$ expression and/or activity provides an advantage for tumor progression not only by inducing EMT, but also by creating an immunosuppressive environment and initiating angiogenesis [Padua and Massagué, 2009]. How important EMT, and more specifically TGF- $\beta$-induced EMT, is in human carcinoma progression, invasion and metastasis remains unclear. Nevertheless, research on the molecular mechanisms and the role of TGF- $\beta$ in EMT and cancer progression has been greatly aided by the characterization of cell culture models for TGF- $\beta$-induced EMT. Among these, the normal murine mammary gland (NMuMG) epithelial cell line is perhaps the best studied cell system. In these cells, addition of TGF- $\beta$ induces an EMT program in cell culture that is completed in $36 \mathrm{~h}$ [Miettinen et al., 1994].

Other members of the TGF- $\beta$ family are also involved in regulating EMT events during development and in cancer, although the knowledge of their roles is currently poorly developed. Bone morphogenetic proteins are involved in EMT processes during gastrulation, neural crest delamination and atrioventricular cushion patterning [Kishigami and Mishina, 2005; Ma et al., 2005; Acloque et al., 2009], and the anti-Müllerian hormone is required for the second phase of Müllerian duct regression [Klattig and Englert, 2007]. In the pathological context, bone morphogenetic proteins have been linked to EMT and invasiveness of several types of cancer cells [Theriault et al., 2007; Gordon et al., 2009], while in other cases, they promote or may be involved in mesenchymal-epithelial transition [Zeisberg et al., 2005].

Discussion of the role of these members of the TGF- $\beta$ family in EMT is beyond the scope of this overview.

\section{TGF- $\beta$-Induced Smad Signaling in EMT}

TGF- $\beta$ signals through a heterotetrameric complex of two TGF- $\beta$ type II (T $\beta R I I)$ and two TGF- $\beta$ type I (T $\beta$ RI) transmembrane dual specificity kinase receptors. Upon TGF- $\beta$ binding to the receptors, T $\beta$ RII activates T $\beta R I$, which in turn phosphorylates and activates the intracellular mediators Smad2 and Smad3. Once activated, Smad2 and/or Smad3 dissociate from the receptor complex and combine with the common Smad, Smad4, to form trimeric complexes of Smad proteins. These translocate to the nucleus where they cooperate with other transcription factors, coactivators or corepressors, to regulate gene transcription (fig. 2). The inhibitory Smad6 and Smad7 block the activation of Smad 2 and Smad 3 by preventing their interaction with TRRI. They do not serve as transcription activators, yet may function as transcription repressors [Shi and Massagué, 2003; Feng and Derynck, 2005]. Consistent with the role of TGF- $\beta$ as inducer of EMT, these receptors and Smads were shown to play a role in EMT.

Expression of a cytoplasmically truncated T $\beta$ RII has been shown to block TGF- $\beta$-induced EMT in normal and cancer epithelial cells through dominant negative interference both in vitro and in vivo [Oft et al., 1998; Portella et al., 1998; Han et al., 2005]. In NMuMG cells, expression of a cytoplasmically truncated T $\beta R I$ similarly inhibits TGF- $\beta$-induced EMT, whereas a constitutively active mutant of T $\beta R I$ induces EMT in the absence of added TGF- $\beta$ [Piek et al., 1999; Valcourt et al., 2005]. Similar to the effect of the dominant negative form of TßRI, a pharmacological inhibitor that represses the kinase activity of T $\beta R I$ prevents TGF- $\beta$-induced EMT [Kondo et al., 2004; Lamouille and Derynck, 2007]. Downstream of the receptors, the Smad effectors mediate gene expression responses that are required for the induction of EMT upon TGF- $\beta$ stimulation [Akhurst, 2008]. Indeed, expression of $S \operatorname{mad} 2$, Smad 3 and Smad4 mutants that can interfere with Smad function, or downregulation of Smad4 expression using RNA interference, was also shown to inhibit the conversion from an epithelial to a mesenchymal phenotype [Valcourt et al., 2005; Deckers et al., 2006]. However, in some cell contexts, Smad2 was reported to act as an antagonist in TGF- $\beta$-induced EMT. For example, Smad2-deficient keratinocytes undergo EMT and promote skin tumor formation through enhanced activities of Smad3 and Smad4 [Hoot et al., 2008; see also Masszi and Kapus, 2011, this issue]. Finally, increased expression of the inhibitory Smad7 represses TGF- $\beta$-induced EMT in various epithelial cells [Valcourt et al., 2005; Zavadil and Böttinger, 2005].

The induction of EMT in response to TGF- $\beta$ has been attributed in part to the Smad transcription complexes that regulate transcription of essential genes involved in this process. Notably, TGF- $\beta$ signaling directly activates the expression of Snail proteins through Smads. Smad3 


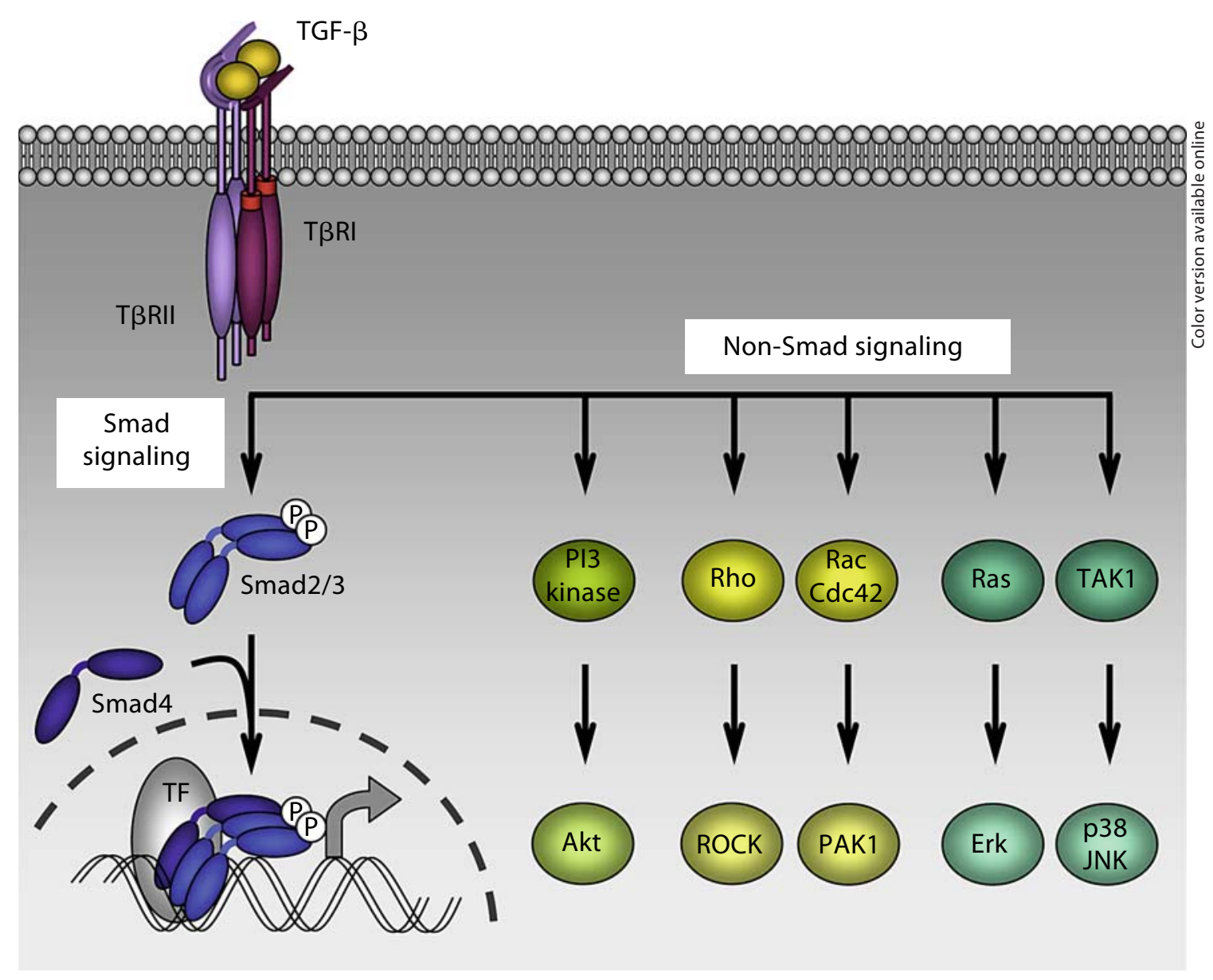

Fig. 2. Smad and non-Smad signaling in TGF- $\beta$-induced EMT. TGF- $\beta$ initiates signaling through 2 pairs of dual specificity kinase receptors that activate the intracellular signal transducers Smad 2 and Smad 3 through direct C-terminal phosphorylation. Following activation, Smad2 and Smad3 combine with Smad4, and these trimeric complexes then translocate into the nucleus and regulate transcription of target genes through interaction with DNA-binding transcription factors (TF), coactivators and corepressors. In addition, TGF- $\beta$ initiates non-Smad signaling pathways such as PI3 kinase-Akt, Rho-like GTPases and MAP kinase pathways. Both Smad and non-Smad signaling pathways are involved in TGF- $\beta$-induced EMT responses.

binds to regulatory promoter sequences of the gene encoding Snaill and activates its transcription [Cho et al., 2007; Hoot et al., 2008]. In addition, Smad 3 and Smad4 form a complex with Snaill that binds to E-box and Smad-binding elements in the promoters of the genes encoding E-cadherin, occludin and the tight junction-associated cell adhesion molecule CAR, consequently repressing their transcription [Vincent et al., 2009]. In cells induced to undergo EMT, TGF- $\beta$ also activates the expression of ZEB transcription factors through upregulation of the expression of the transcription factor Ets1, which then may cooperate with the bHLH transcription factor E47 [Shirakihara et al., 2007]. Moreover, the expression of the miR-200 microRNAs is downregulated in
TGF- $\beta$-induced EMT, resulting in an increase in translation of the ZEB1 and ZEB2 mRNAs [Gregory et al., 2008]. In addition, expression of ZEB1 and ZEB2 directly represses the transcription of the miR-200 family through binding to ZEB-type E-box motifs in a compact region of the miR-200 family promoter [Bracken et al., 2008; Burk et al., 2008]. TGF- $\beta$ signaling also regulates the activities of the bHLH family of transcription factors during EMT by repressing the expression of Id factors. In the case of Id1, a complex formed by Smad3, Smad4 and the transcription repressor ATF3, binds sequences in the Id1 promoter and represses its transcription [Kang et al., 2003]. The decrease in expression of Id factors then increases activity of E-proteins and Twist, resulting in transcrip- 
tional repression of the E-cadherin gene. Finally, the transcription factor HMGA2, whose expression increases during TGF- $\beta$-induced EMT through a Smad3/ Smad4-dependent mechanism, has also emerged as an essential mediator in TGF- $\beta$-induced EMT by enhancing the expression of Snail and Twist proteins, and by repressing the expression of Id2 [Thuault et al., 2006].

\section{Non-Smad Signaling in TGF- $\beta$-Induced EMT}

In addition to Smad signaling, which directly targets transcriptional regulation, TGF- $\beta$ initiates non-Smad signaling pathways (fig. 2) [Derynck and Zhang, 2003; Moustakas and Heldin, 2005]. These pathways include the 3 mitogen-activated protein (MAP) kinase pathways that lead to activation of extracellular-regulated kinase (Erk), p38 and JNK. However, these pathways are generally more prominently activated by tyrosine kinase receptors, principally in response to growth factor stimulation. Activation of these pathways complements the Smad signaling responses to regulate essential aspects of TGF$\beta$-induced EMT, such as cytoskeleton reorganization, and cell migration and invasion. Their synergy with TGF- $\beta /$ Smad signaling in inducing EMT has been well illustrated through the cooperation of tyrosine kinase receptor activation with TGF- $\beta$ signaling. For example, epidermal growth factor stimulates Ras and Erk MAP kinase signaling, which enhances TGF- $\beta$-induced EMT responses such as repression of E-cadherin expression and activation of Snail2, N-cadherin and matrix metalloproteinase expression [Grande et al., 2002; Schmidt et al., 2005; Uttamsingh et al., 2008]. Accordingly, pharmacological inhibition of MEK proteins, which activate Erk MAP kinase, prevents the EMT process induced by TGF$\beta$ [Xie et al., 2004]. Chemical inhibitors of p38 MAP kinase or JNK MAP kinase, and antisense oligonucleotides targeting JNK, have also been reported to block TGF- $\beta$ induced EMT as observed with morphological changes and epithelial versus mesenchymal marker regulation [Bakin et al., 2002; Yu et al., 2002; Santibanez, 2006; Alcorn et al., 2008].

TGF- $\beta$ activates the Ras-Raf-MEK-Erk MAP kinase pathway through the association of ShcA with the TGF- $\beta$ receptor complex and direct serine and threonine phosphorylation of ShcA by T $\beta R I$ in response to TGF- $\beta$. The phosphorylated tyrosines on ShcA provide a docking site for the recruitment of Grb2 and Sos, and this complex initiates Ras activation leading to Erk MAP kinase signaling cascade [Lee et al., 2007]. TGF- $\beta$ has been shown to induce p38 and JNK MAP kinase signaling through activation of TAK1 by the ubiquitin ligase TRAF6 that interacts with the TGF- $\beta$ receptor complex [Sorrentino et al., 2008; Yamashita et al., 2008]. The recent characterization of how these MAP kinase pathways are activated in response to TGF- $\beta$ should enable a dissection of their relative contributions to TGF- $\beta$-induced EMT.

TGF- $\beta$ also regulates the activity of the small GTPase proteins Rho, Rac and Cdc42, which function as key signaling mediators in the reorganization of the actin cytoskeleton and the formation of lamellipodia and filopodia, actin protrusions that are required for cell migration [Bhowmick et al., 2001; Zavadil and Böttinger, 2005; Yilmaz and Christofori, 2009]. The mechanisms underlying regulation of the small GTPases by TGF- $\beta$ receptor activation remain poorly characterized. In the early stage of TGF- $\beta$-induced EMT, the polarity molecule Par6 interacts at tight junctions with T $\beta R I$, and the phosphorylation of T $\beta R I$ by T $\beta$ RII recruits the E3 ubiquitin ligase Smurf1 which mediates the ubiquitination and consequently the degradation of RhoA during tight junction disruption [Ozdamar et al., 2005]. In addition, the microRNA miR-155 that targets RhoA expression is upregulated in TGF- $\beta$-induced EMT [Kong et al., 2008]. However, during EMT, TGF- $\beta$ also activates RhoA and its downstream targets rho-associated coiled-coil containing protein kinase (ROCK) and LIM kinase, mediators of actin stress fiber formation [Vardouli et al., 2005; Pellegrin and Mellor, 2007]. Indeed, antisense oligonucleotides that downregulate the expression of ROCK or LIM kinase, and pharmacological inhibition of ROCK, inhibit the actin reorganization that accompanies TGF- $\beta$-induced EMT [Bhowmick et al., 2001; Tavares et al., 2006; Cho and Yoo, 2007].

Finally, TGF- $\beta$ induces Akt activation through phosphoinositide 3 (PI3) kinase during EMT [Bakin et al., 2000; Lamouille and Derynck, 2007]. Once activated, Akt initiates signaling pathways such as the mammalian target of rapamycin (mTOR) pathway, that play roles in cell survival, growth, migration and invasion. The essential role of TGF- $\beta$-induced PI3 kinase-Akt-mTOR signaling in the context of EMT is discussed in the remainder of this review.

\section{The TGF- $\beta$-PI3 Kinase-Akt-mTOR Axis in EMT}

A variety of tyrosine kinase receptors for growth factors, such as epidermal growth factor, fibroblast growth factor, insulin-like growth factor-1 and insulin, activate 
signaling through the PI3 kinase-Akt pathway. Moreover, activation of PI3 kinase and Akt signaling has been detected in cells undergoing EMT [Larue and Bellacosa, 2005]. We and others have observed that TGF- $\beta$ induces the PI3 kinase-Akt pathway in various cell types, including cells that undergo TGF- $\beta$-induced EMT [Bakin et al., 2000; Lee et al., 2004; Lien et al., 2006; Rodriguez-Barbero et al., 2006; Lamouille and Derynck, 2007; Lin et al., 2007; Yeh et al., 2008]. These observations raise the question as to what role the activation of PI3 kinase-Akt signaling plays in TGF- $\beta$-induced EMT.

Activation of PI3 kinase results in the generation of phosphatidylinositol $(3,4,5)$-triphosphate (PIP3), which provides a phospholipid binding site for proteins that contain a pleckstrin homology domain, such as Akt. Once Akt is recruited to the plasma membrane, it is fully activated upon phosphorylation on a threonine by the kinase PDK1, and on a serine principally by mTOR in mTOR complex 2 (mTORC2). In some cell models, Akt may also be activated by integrin-linked kinase, a cytoplasmic kinase that relays signals between integrins and the actin cytoskeleton, and integrin-linked kinase function may be required for EMT [McDonald et al., 2008]. The 3 Akt kinases in mammalian cells (Akt1, Akt2 and Akt3) can phosphorylate a range of proteins that regulate physiological processes such as cell survival, growth, metabolism and migration. However, these Akt proteins display distinct functions, based on gene targeting studies [Gonzalez and McGraw, 2009]. In cell culture, downregulation of Akt2 expression blocks the phenotypical changes and cell migration increase that accompany insulin-like growth factor-1-dependent EMT, while downregulating Aktl expression enhances this effect [Irie et al., 2005]. In the same epithelial cell model, decreased Akt1 expression promotes TGF- $\beta$-induced EMT through a decrease in abundance of the miR-200 family [Iliopoulos et al., 2009]. Interestingly, TGF- $\beta_{2}$ selectively activates Akt2 but not Akt1 in NMuMG cells [Chaudhury et al., 2010]. However, the role of Akt in EMT, cell migration and invasion may differ depending on the TGF- $\beta$ isoform and cell model used.

A downstream target of Akt proteins is glycogen synthase kinase-3 $\beta$ (GSK-3 $\beta$ ), a kinase that binds to and phosphorylates Snaill, resulting in enhanced cytoplasmic retention and degradation of Snail1. Phosphorylation of GSK-3 $\beta$ by Akt results in its ubiquitination and degradation, leading to increased accumulation of Snaill in the nucleus and repression of E-cadherin expression, consequently inducing EMT [Zhou et al., 2004; Bachelder et al., 2005]. In addition, Akt induces transcription of the Snaill gene, through nuclear factor- $\kappa \mathrm{B}$ activation, in squamous cell carcinoma lines that undergo EMT [Julien et al., 2007]. The nuclear factor- $\kappa B$ pathway can also promote EMT, invasion and metastasis in murine mammary cells transformed with $\mathrm{H}$-Ras. Interestingly, interference with nuclear factor- $\kappa \mathrm{B}$ activity in this cell model prevents TGF- $\beta$-induced EMT [Huber et al., 2004]. Akt also phosphorylates TSC2 in the TSC2-TSC1 complex, thus inhibiting its function as GTPase-activating protein toward the small GTPase protein Rheb. As a result, accumulation of Rheb-GTP activates the kinase mTOR in a complex called 'mTOR complex 1' (mTORC1) [Laplante and Sabatini, 2009]. Two major kinase targets of mTORC1 have been characterized: S6 kinases and 4E-BP1. The phosphorylation of S6 kinases 1 and 2 by mTORC1 regulates translation initiation and ribosome biogenesis, notably through activation of downstream targets such as the ribosomal protein S6 [Hay and Sonenberg, 2004; Holz et al., 2005]. Phosphorylation of 4E-BP1 by mTORC1 releases the eukaryotic translation initiation factor eIF4E from its interaction with $4 \mathrm{E}-\mathrm{BP} 1$, thus initiating cap-dependent translation of mRNAs, such as the mRNA for cyclin D1, which is involved in cell cycle progression and proliferation [Hay and Sonenberg, 2004; Robert and Pelletier, 2009]. Therefore, activation of mTORC1 results in enhanced protein synthesis and, consequently, increased cell size. mTORC1 is activated not only in response to growth factors, but also responds to nutrients, amino acids and stress signals [Laplante and Sabatini, 2009].

Besides mTORC1 that comprises mTOR, mLST8 and Raptor, mTOR can also form a complex with mLST8, Rictor, mSinl and Protor. The biology of this second complex named 'mTORC2' is less characterized when compared with mTORC1 [Laplante and Sabatini, 2009]. As mentioned already, mTORC2 mediates Akt phosphorylation, contributing to its full activation [Sarbassov et al., 2005]. It also phosphorylates protein kinase $\mathrm{C} \alpha$ and is believed to regulate the cytoskeletal organization by regulating Rho and Rac activities [Jacinto et al., 2004; Sarbassov et al., 2004]. Rapamycin acts as a specific inhibitor of mTORC1 activity and interferes with the recruitment and activation of mTORC1 targets, possibly by destabilizing the interaction of Raptor with mTOR. Rapamycin does not inhibit the activity of mTORC2, although prolonged rapamycin exposure can decrease mTORC2 activity by destabilizing the assembly of the regulatory components of this complex [Guertin and Sabatini, 2007].

We and others observed that TGF- $\beta$ induces increases in cell size and protein content in various cell types, including epithelial cells that undergo EMT in response to 


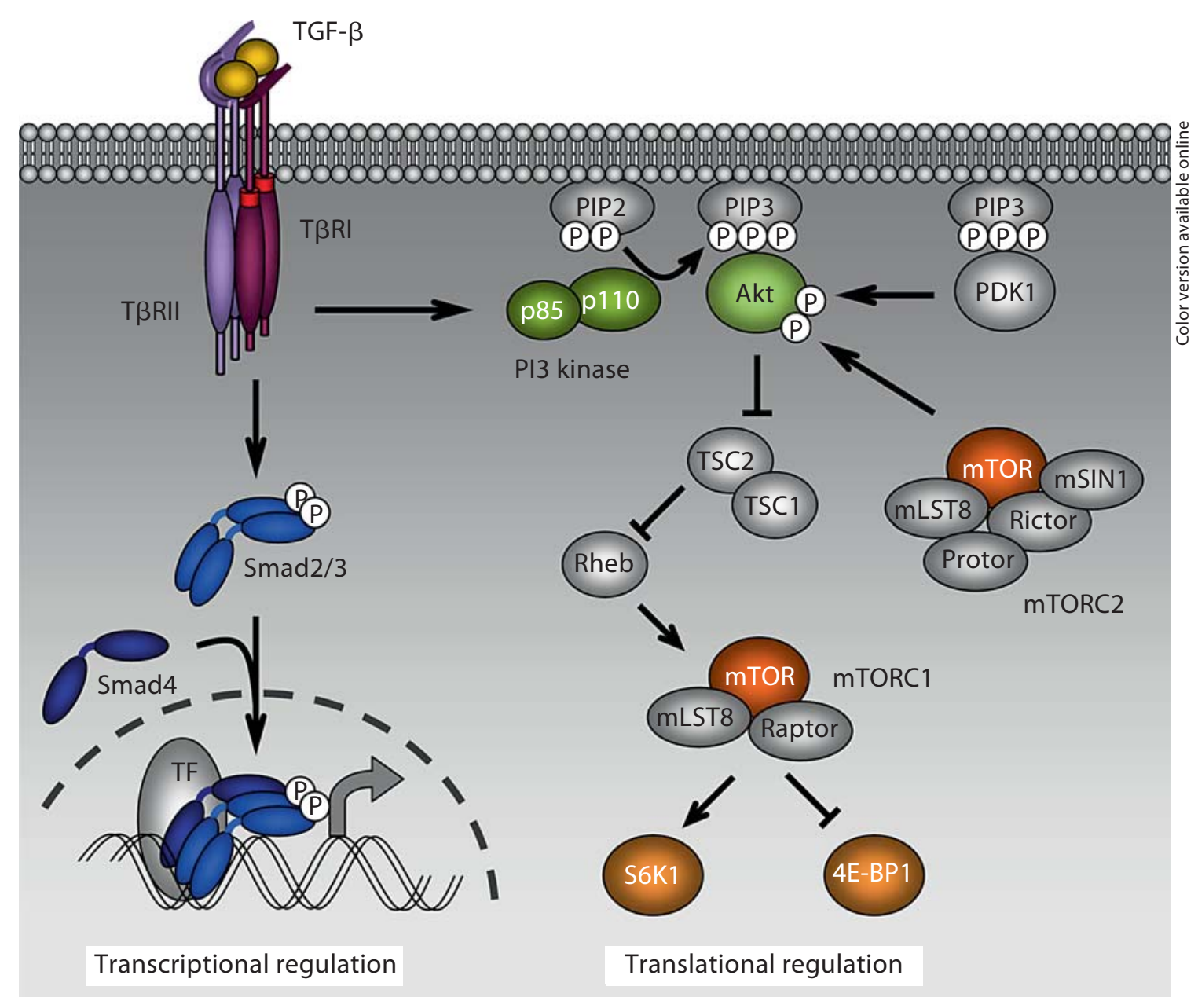

Fig. 3. PI 3 kinase-Akt-mTOR signaling in TGF- $\beta$-induced EMT. During EMT, TGF- $\beta$ activates mTORC1 in a PI3 kinase-Akt-dependent manner. This results in increases in protein synthesis, via phosphorylation of mTORC1 targets such as S6 kinase 1 (S6K1) and 4E-BP1, cell size, motility and invasion. This translational regulation complements the Smad-dependent transcriptional regulation. mTORC2 phosphorylates Akt, thus contributing to its activation, but its exact role in TGF- $\beta$-induced EMT remains to be discovered.

TGF- $\beta$ [Lamouille and Derynck, 2007; Das et al., 2008; $\mathrm{Wu}$ and Derynck, 2009]. These increases were apparent in 2 models of TGF- $\beta$-induced EMT, the murine mammary gland NMuMG cells and the human HaCaT keratinocytes. In these cells, we also detected a TGF- $\beta$-induced activation of mTOR resulting in phosphorylation of the 2 targets of mTORC1, S6 kinase 1 and 4E-BP1, through the activation of PI3 kinase and Akt (fig. 3) [Lamouille and Derynck, 2007]. How TGF- $\beta$ signaling links to activation of PI3 kinase is as yet unclear, although PI3 kinase has been found in association with the activated TGF- $\beta$ receptor complex [Yi et al., 2005]. The increases in cell size and protein content in response to TGF- $\beta$ are mediated by the activation of mTORC1, and accordingly, rapamycin inhibits the TGF- $\beta$-induced cell size and the protein content increases [Lamouille and Derynck, 2007]. The activation of S6 kinase 1 and 4E-BP1 is most likely responsible for the increased protein synthesis that occurs during TGF- $\beta$-induced EMT. These observations demonstrate that TGF- $\beta$ regulates translation via PI3 kinase, Akt and mTORC1 during EMT. The activation of this translation pathway complements the transcriptional regulation through Smad signaling (fig. 3). Whereas the activation of translation by $\mathrm{mTORC1}$ in response to TGF- $\beta$ may complement the increased Smad-mediated transcriptional responses, it may also allow for selective translational control of target genes that potentially play a role in the phenotype and behavior of cells that have 
undergone EMT. Interestingly, increased S6 kinase 1 activity enhances EMT and invasion in human ovarian cancer cells through induction of Snaill expression at the transcriptional level, but the mechanism of such regulation remains unclear [Pon et al., 2008].

To further define the role of the activation of mTORC1 in TGF- $\beta$-induced EMT, we treated NMuMG and HaCaT cells with TGF- $\beta$ to induce EMT, in the presence of rapamycin. While the cells did not increase in size and protein content, the inhibition of mTORC1 did not block the morphological changes associated with EMT. Accordingly, similar to cells in the absence of rapamycin, TGF- $\beta$ induced cell shape changes, accompanied with cytoskeletal reorganization, dissolution of the junctions with delocalization of E-cadherin and zona occludens-1, and induction of mesenchymal markers such as fibronectin and $\mathrm{N}$-cadherin. Besides the morphological and gene expression changes, EMT is accompanied by a change in cell behavior, specifically migration and invasion. However, when mTORC1 activity is blocked using rapamycin in cell culture, the cells that have undergone EMT do not show the increases in migration and invasion that normally accompany EMT [Lamouille and Derynck, 2007]. Perhaps the increased protein synthesis that follows mTORC1 activation may participate in the enhanced expression of specific proteins that act directly or indirectly in cell migration and invasion, such as matrix metalloproteinases. Therefore, activation of mTORC1 downstream of PI3 kinase-Akt and in response to TGF- $\beta$ contributes to EMT in 2 ways. While it mediates the increase in protein synthesis and cell size during EMT, mTORC1 activity is also essential for the increased motility and invasion of cells that have undergone EMT. Since increased invasion plays a key role in cancer progression toward metastasis, these results highlight a role for AktmTOR signaling in cancer progression, independent of cell proliferation regulation. Therefore, rapamycin analogs or other inhibitors of mTOR activity may aid in preventing invasion, cancer progression and metastasis. In line with our observations, rapamycin has been found to inhibit the downregulation of E-cadherin expression in mesothelial cells that undergo TGF- $\beta$-induced EMT [Aguilera et al., 2005], and to block motility in some other cell models [Liu et al., 2006; Gulati et al., 2009]. On the other hand, the rapamycin-insensitive mTORC2 is believed to play a role in cytoskeleton arrangement through the regulation of Rho, Rac and protein kinase $\mathrm{C} \alpha$ activities [Jacinto et al., 2004; Sarbassov et al., 2004]. Therefore, it is conceivable that this complex could be involved in the process of actin cytoskeleton reorganization that occurs during TGF- $\beta$-induced EMT. Interestingly, decreased activity of mTORC2 inhibits the migratory behavior of breast cancer cells [Qiao et al., 2007]. Additional studies will be needed to decipher a possible implication of mTORC2 in EMT and the mechanisms that regulate its activation.

\section{TGF- $\beta$ Signaling and the PI3 Kinase-Akt-mTOR Pathway in Cancer}

In epithelial cells, TGF- $\beta$ signaling leads to inhibition of cell proliferation, which serves as an autocrine tumor suppressor function, while other signaling responses can promote the transition toward carcinoma cells and aid in cancer progression. An early event in the transition from epithelial to carcinoma cells is the inactivation of the tumor suppressor effect of TGF- $\beta$ [Bierie and Moses, 2006b; Nguyen and Massagué, 2007]. Mutations in T $\beta R I I$ and T $\beta R I$ receptors, as well as in TGF- $\beta$ Smads, have been observed in carcinomas and inactivate the growth inhibitory activity of TGF- $\beta$. In addition, alterations in downstream components of Smad signaling have been shown to result in a similar effect without inactivating other TGF- $\beta$ responses that are beneficial to the tumor cells [Bierie and Moses, 2006a]. As cancer cells often have increased expression and activation of TGF- $\beta$, the autocrine responses of carcinoma cells to TGF- $\beta$, in particular the loss of the epithelial phenotype and induction of EMT, are thought to play an important role in driving the invasive behavior of carcinoma cells and progression toward metastasis [Derynck et al., 2001; Nguyen and Massagué, 2007]. Accordingly, expression of dominant negative TRRII receptor in metastatic cell lines inhibits EMT in vitro and in vivo [Oft et al., 1998; Portella et al., 1998; Han et al., 2005]. Therefore, TGF- $\beta$-induced EMT correlates with tumor metastasis through an increase in cellinvasive characteristics.

The complexity of the TGF- $\beta$ signaling responses, and the dual nature of their effects on epithelial cancer cells, i.e. tumor suppression versus cancer progression, has made the development of anti-cancer approaches based on inhibition of TGF- $\beta$ signaling challenging. Nevertheless, T $\beta$ RI kinase inhibitors, neutralizing TGF- $\beta$ antibodies and the dimerized T $\beta R I I$ extracellular domain fused to human IgG Fc domain, are being evaluated in preclinical and clinical trials as inhibitors of cancer progression [Bonafoux and Lee, 2009]. Rather than developing approaches to block all TGF- $\beta$ signaling and cellular responses, it is preferable to selectively target the TGF- $\beta$ - 
induced promotion of invasion and metastasis of cancer cells, thereby avoiding an inactivation of the tumor suppression function of TGF- $\beta$. Our insights into the role of Akt-mTOR signaling in TGF- $\beta$-induced EMT, and in particular invasion, may provide a basis for such a targeted approach.

Deregulation and increased activities of PI3 kinase and Akt have been linked to tumorigenesis and cancer progression. The gene encoding the catalytic subunit p110 $\alpha$ of PI3 kinase is frequently mutated in human tumors, resulting in increased PIP3 production and, consequently, increased Akt signaling. Mutations in the gene encoding the PI3 kinase regulatory subunit $\mathrm{p} 85 \alpha$ have also been identified, and these lead to constitutive PI3 kinase activity [Liu et al., 2009]. Moreover, amplification of Akt genes or overexpression of Akt has been observed in a range of human tumors and is generally associated with poor prognosis. Recently, mutations in the pleckstrin homology domain of Akt1 that lead to growth factor-independent anchoring to the plasma membrane and increased Akt1 phosphorylation have been identified in several cancers [Gonzalez and McGraw, 2009]. Finally, loss of the tumor suppressor PTEN, a phosphatase that antagonizes PI3 kinase activity by dephosphorylating PIP3, is commonly observed in cancer progression [Liu et al., 2009]. These and many other findings link an increase in PI3 kinase and Akt signaling to tumorigenesis and to increased cell survival and decreased apoptosis.

Increased and deregulated mTORC1 and mTORC2 activities have also been observed in tumors and linked to cancer progression. In a tightly controlled manner, mTORC1 regulates the synthesis of proteins involved in cell cycle progression, apoptosis, invasion and angiogenesis. A deregulation of mTORC1-dependent translation initiation consequently allows for enhanced tumor growth and metastasis. Accordingly, increased levels and phosphorylation of downstream targets of $\mathrm{mTORC} 1$ have been correlated with tumor aggressiveness in various human malignancies [Guertin and Sabatini, 2007]. In addition, mTORC2 phosphorylates Akt, and this phosphorylation, together with the phosphorylation of Akt by PDK1, results in full Akt activation [Sarbassov et al., 2005]. Although the mechanism of mTORC2 activation requires further characterization, the elevated Akt phosphorylation observed in various human tumors may be explained by a hyperactivation of mTORC2. It has recently been shown that $\mathrm{mTORC} 2$ is required for tumor initiation in a model of prostate cancer cells in PTEN-deficient mouse [Guertin et al., 2009].
Because of the frequently observed deregulation in PI3 kinase-Akt-mTOR signaling in human cancers, and its link to increased cell proliferation and survival, the PI3 kinase-Akt-mTOR pathway has been extensively targeted in the development of cancer therapies. Wortmannin and LY294002 represented a first generation of PI3 kinase inhibitors, but their lack of selectivity and high toxicity made these drugs unsuitable for the treatment of cancers. Recently, more isoform-specific chemical inhibitors of PI3 kinase have been developed, with some also targeting the mTOR kinase. For example, PI-103 inhibits the activities of $\mathrm{p} 110 \alpha$ and $\mathrm{mTOR}$, and its use for cancer therapy is being explored [Liu et al., 2009]. With its central role, Akt is also considered an attractive therapeutic target. Accordingly, several Akt inhibitors are currently in clinical trials for cancer treatment. They comprise lipid-based phosphatidylinositol analogs that prevent the localization of Akt to the plasma membrane, ATP-competitive kinase inhibitors and allosteric inhibitors [Liu et al., 2009]. Rapamycin is a natural inhibitor of mTORC1 but its poor solubility led pharmaceutical companies to develop analogs with improved pharmacokinetic properties, some of which are already in clinical use [Guertin and Sabatini, 2009]. Whereas rapamycin inhibits the activity of mTORC1, it does not block the activities of mTORC2, although prolonged exposure to rapamycin can affect the assembly of mTORC2 components [Guertin and Sabatini, 2007]. However, mTORC2 activity has been shown to be enhanced following inhibition of mTORC1, as observed by Akt hyperphosphorylation following rapamycin treatment in several cell models. Therefore, it may be imperative to also target mTORC2. Consequently, pharmacological kinase inhibitors of mTOR that inhibit both mTORC1 and mTORC2 have recently been developed and are clinically evaluated as therapy to cancer progression [Guertin and Sabatini, 2009].

\section{Conclusions and Perspectives}

The realization that TGF- $\beta$ activates signaling through the PI3 kinase-Akt-mTOR axis and that this pathway is required for EMT and invasion now opens several opportunities, yet also leads to new questions. Our current data suggest that, in TGF- $\beta$-induced EMT, activation of mTOR signaling is required for motility and invasion, raising the possibility that inhibition of mTOR activity may prevent cancer dissemination. While such an approach may not block the cell morphological changes of 
EMT, inhibiting the invasion process at the very basis of cancer progression may represent an avenue of selectively inhibiting the cancer-promoting effects of TGF- $\beta$ without the concern of relieving the tumor suppressor activity of TGF- $\beta$. The current findings also raise a number of new questions about the molecular mechanisms and functions associated with TGF- $\beta$-induced PI3 kinase-Akt-mTOR signaling. How activation of the TGF- $\beta$ receptor complex leads to activation of PI3 kinase-AktmTOR signaling is currently unclear, nor do we know which PI3 kinase or Akt proteins are involved. Inhibition of $\mathrm{mTORC1}$ represents an attractive approach for the prevention of EMT-associated cell motility and invasion, and in uncovering novel effectors of this process which lie under mTORC1 selective translational regulation. Such a strategy should provide insight into the link between TGF- $\beta$-induced EMT and the mechanisms underlying cancer progression.

\section{Acknowledgments}

We are grateful to J. Smyth and J. Xu for their critical review of the manuscript. This research was supported by grants RO1CA136690 and PO1-HL60231 (project III) to R. Derynck, a postdoctoral fellowship grant (grant 5566-07) from the Leukemia and Lymphoma Society and a scientist development grant (grant 09SDG2280008) from the American Heart Association to S. Lamouille.

\section{References}

Acloque, H., M.S. Adams, K. Fishwick, M. Bronner-Fraser, M.A. Nieto (2009) Epithelialmesenchymal transitions: the importance of changing cell state in development and disease. J Clin Invest 119: 1438-1449.

-Aguilera, A., L.S. Aroeira, M. Ramirez-Huesca, M.L. Perez-Lozano, A. Cirugeda, M.A. Bajo, G. Del Peso, A. Valenzuela-Fernandez, J.A. Sanchez-Tomero, M. Lopez-Cabrera, R. Selgas (2005) Effects of rapamycin on the epithelial-to-mesenchymal transition of human peritoneal mesothelial cells. Int J Artif Organs 28: 164-169.

Akhurst, R.J. (2008) TGF- $\beta$ signaling in epithelial-mesenchymal transition and invasion and metastasis; in Derynck, R., K. Miyazono (eds) The TGF- $\beta$ Family. New York, Cold Spring Harbor Laboratory Press, pp 939964.

-Alcorn, J.F., A.S. Guala, J. van der Velden, B. McElhinney, C.G. Irvin, R.J. Davis, Y.M. Janssen-Heininger (2008) Jun N-terminal kinase 1 regulates epithelial-to-mesenchymal transition induced by TGF- $\beta_{1}$. J Cell Sci 121: 1036-1045

Azhar, M., J. Schultz Jel, I. Grupp, G.W. Dorn, 2nd, P. Meneton, D.G. Molin, A.C. Gittenberger-de Groot, T. Doetschman (2003) Transforming growth factor- $\beta$ in cardiovascular development and function. Cytokine Growth Factor Rev 14: 391-407.

Bachelder, R.E., S.O. Yoon, C. Franci, A.G. de Herreros, A.M. Mercurio (2005) Glycogen synthase kinase-3 is an endogenous inhibitor of Snail transcription: implications for the epithelial-mesenchymal transition. J Cell Biol 168: 29-33.

Bakin, A.V., C. Rinehart, A.K. Tomlinson, C.L. Arteaga (2002) p38 mitogen-activated protein kinase is required for TGF- $\beta$-mediated fibroblastic transdifferentiation and cell $\mathrm{mi}-$ gration. J Cell Sci 115: 3193-3206.
Bakin, A.V., A.K. Tomlinson, N.A. Bhowmick, H.L. Moses, C.L. Arteaga (2000) Phosphatidylinositol 3-kinase function is required for transforming growth factor- $\beta$-mediated epithelial to mesenchymal transition and cell migration. J Biol Chem 275: 36803-36810.

Barrallo-Gimeno, A., M.A. Nieto (2005) The Snail genes as inducers of cell movement and survival: implications in development and cancer. Development 132: 3151-3161.

Batlle, E., E. Sancho, C. Franci, D. Dominguez, M. Monfar, J. Baulida, A. Garcia De Herreros (2000) The transcription factor snail is a repressor of E-cadherin gene expression in epithelial tumour cells. Nat Cell Biol 2: 84-89.

Bhowmick, N.A., M. Ghiassi, A. Bakin, M Aakre, C.A. Lundquist, M.E. Engel, C.L. Arteaga, H.L. Moses (2001) Transforming growth factor- $\beta_{1}$ mediates epithelial to mesenchymal transdifferentiation through a RhoA-dependent mechanism. Mol Biol Cell 12: 27-36.

Bierie, B., H.L. Moses (2006a) TGF- $\beta$ and cancer. Cytokine Growth Factor Rev 17: 29-40.

Bierie, B., H.L. Moses (2006b) Tumour microenvironment: TGF- $\beta$ : the molecular Jekyll and Hyde of cancer. Nat Rev Cancer 6: 506-520.

Bonafoux, D., W.C. Lee (2009) Strategies for TGF- $\beta$ modulation: a review of recent patents. Expert Opin Ther Pat 19: 1759-1769.

Bracken, C.P., P.A. Gregory, N. Kolesnikoff, A.G. Bert, J. Wang, M.F. Shannon, G.J. Goodall (2008) A double-negative feedback loop between ZEB1-SIP1 and the microRNA-200 family regulates epithelial-mesenchymal transition. Cancer Res 68: 7846-7854.

Burk, U., J. Schubert, U. Wellner, O. Schmalhofer, E. Vincan, S. Spaderna, T. Brabletz (2008) A reciprocal repression between ZEB1 and members of the miR-200 family promotes EMT and invasion in cancer cells. EMBO Rep 9: 582-589.
Cano, A., M.A. Perez-Moreno, I. Rodrigo, A. Locascio, M.J. Blanco, M.G. del Barrio, F. Portillo, M.A. Nieto (2000). The transcription factor snail controls epithelial-mesenchymal transitions by repressing E-cadherin expression. Nat Cell Biol 2: 76-83.

Chaudhury, A., G.S. Hussey, P.S. Ray, G. Jin, P.L. Fox, P.H. Howe (2010) TGF- $\beta$-mediated phosphorylation of hnRNP E1 induces EMT via transcript-selective translational induction of Dab2 and ILEI. Nat Cell Biol 12: 286293.

Cho, H.J., K.E. Baek, S. Saika, M.J. Jeong, J. Yoo (2007) Snail is required for transforming growth factor- $\beta$-induced epithelial-mesenchymal transition by activating PI3 kinase/ Akt signal pathway. Biochem Biophys Res Commun 353: 337-343.

Cho, H.J., J. Yoo (2007) Rho activation is required for transforming growth factor- $\beta$-induced epithelial-mesenchymal transition in lens epithelial cells. Cell Biol Int 31: 12251230

Comijn, J., G. Berx, P. Vermassen, K. Verschueren, L. van Grunsven, E. Bruyneel, M. Mareel, D. Huylebroeck, F. van Roy (2001) The two-handed E box binding zinc finger protein SIP1 downregulates E-cadherin and induces invasion. Mol Cell 7: 1267-1278.

Cui, W., D.J. Fowlis, S. Bryson, E. Duffie, H. Ireland, A. Balmain, R.J. Akhurst (1996) TGF$\beta_{1}$ inhibits the formation of benign skin tumors, but enhances progression to invasive spindle carcinomas in transgenic mice. Cell 86: 531-542.

Das, F., N. Ghosh-Choudhury, L. Mahimainathan, B. Venkatesan, D. Feliers, D.J. Riley, B.S. Kasinath, G.G. Choudhury (2008) Raptor-rictor axis in TGF- $\beta$-induced protein synthesis. Cell Signal 20: 409-423. 
Deckers, M., M. van Dinther, J. Buijs, I. Que, C. Lowik, G. van der Pluijm, P. ten Dijke (2006) The tumor suppressor Smad4 is required for transforming growth factor- $\beta$-induced epithelial to mesenchymal transition and bone metastasis of breast cancer cells. Cancer Res 66: 2202-2209.

Derynck, R., R.J. Akhurst, A. Balmain (2001) TGF- $\beta$ signaling in tumor suppression and cancer progression. Nat Genet 29: 117-129.

Derynck, R., Y.E. Zhang (2003) Smad-dependent and Smad-independent pathways in TGF- $\beta$ family signaling. Nature 425: 577-584.

-Eger, A., K. Aigner, S. Sonderegger, B. Dampier, S. Oehler, M. Schreiber, G. Berx, A. Cano, H. Beug, R. Foisner (2005) DeltaEF1 is a transcriptional repressor of E-cadherin and regulates epithelial plasticity in breast cancer cells. Oncogene 24: 2375-2385.

Feng, X.H., R. Derynck (2005) Specificity and versatility in TGF- $\beta$ signaling through Smads. Annu Rev Cell Dev Biol 21: 659-693.

Gonzalez, E., T.E. McGraw (2009) The Akt kinases: isoform specificity in metabolism and cancer. Cell Cycle 8: 2502-2508.

Gordon, K.J., K.C. Kirkbride, T. How, G.C. Blobe (2009) Bone morphogenetic proteins induce pancreatic cancer cell invasiveness through a Smad1-dependent mechanism that involves matrix metalloproteinase-2. Carcinogenesis 30: 238-248.

Grande, M., A. Franzen, J.O. Karlsson, L.E. Ericson, N.E. Heldin, M. Nilsson (2002) Transforming growth factor- $\beta$ and epidermal growth factor synergistically stimulate epithelial to mesenchymal transition (EMT) through a MEK-dependent mechanism in primary cultured pig thyrocytes. J Cell Sci 115: 4227-4236.

Gregory, P.A., A.G. Bert, E.L. Paterson, S.C. Barry, A. Tsykin, G. Farshid, M.A. Vadas, Y. Khew-Goodall, G.J. Goodall (2008) The miR-200 family and miR-205 regulate epithelial to mesenchymal transition by targeting ZEB1 and SIP1. Nat Cell Biol 10: 593-601.

-Gressner, A.M., R. Weiskirchen, K. Breitkopf, S. Dooley (2002) Roles of TGF- $\beta$ in hepatic fibrosis. Front Biosci 7: d793-d807.

-Guertin, D.A., D.M. Sabatini (2007) Defining the role of mTOR in cancer. Cancer Cell 12: 9-22.

Guertin, D.A., D.M. Sabatini (2009) The pharmacology of mTOR inhibition. Sci Signal 2: pe24.

Guertin, D.A., D.M. Stevens, M. Saitoh, S. Kinkel, K. Crosby, J.H. Sheen, D.J. Mullholland, M.A. Magnuson, H. Wu, D.M. Sabatini (2009) mTOR complex 2 is required for the development of prostate cancer induced by Pten loss in mice. Cancer Cell 15: 148-159.

-Gulati, N., M. Karsy, L. Albert, R. Murali, M. Jhanwar-Uniyal (2009) Involvement of mTORC1 and mTORC2 in regulation of glioblastoma multiforme growth and motility. Int J Oncol 35: 731-740.
Han, G., S.L. Lu, A.G. Li, W. He, C.L. Corless, M. Kulesz-Martin, X.J. Wang (2005) Distinct mechanisms of TGF- $\beta_{1}$-mediated epithelialto-mesenchymal transition and metastasis during skin carcinogenesis. J Clin Invest 115: 1714-1723.

-Hay, N., N. Sonenberg (2004) Upstream and downstream of mTOR. Genes Dev 18: 1926 1945.

-Holz, M.K., B.A. Ballif, S.P. Gygi, J. Blenis (2005) mTOR and S6K1 mediate assembly of the translation preinitiation complex through dynamic protein interchange and ordered phosphorylation events. Cell 123: 569-580.

Hoot, K.E., J. Lighthall, G. Han, S.L. Lu, A. Li, W. Ju, M. Kulesz-Martin, E. Böttinger, X.J. Wang (2008) Keratinocyte-specific Smad2 ablation results in increased epithelialmesenchymal transition during skin cancer formation and progression. J Clin Invest 118 2722-2732.

Huber, M.A., N. Azoitei, B. Baumann, S. Grunert, A. Sommer, H. Pehamberger, N. Kraut, H. Beug, T. Wirth (2004) NF-kappaB is essential for epithelial-mesenchymal transition and metastasis in a model of breast cancer progression. J Clin Invest 114: 569-581.

Iliopoulos, D., C. Polytarchou, M. Hatziapostolou, F. Kottakis, I.G. Maroulakou, K. Struhl, P.N. Tsichlis (2009) MicroRNAs differentially regulated by Akt isoforms control EMT and stem cell renewal in cancer cells. Sci Signal 2: ra62.

Irie, H.Y., R.V. Pearline, D. Grueneberg, M. Hsia P. Ravichandran, N. Kothari, S. Natesan, J.S. Brugge (2005) Distinct roles of Akt1 and Akt 2 in regulating cell migration and epithelial-mesenchymal transition. J Cell Biol 171: 1023-1034.

Iwano, M., D. Plieth, T.M. Danoff, C. Xue, H Okada, E.G. Neilson (2002) Evidence that fibroblasts derive from epithelium during tissue fibrosis. J Clin Invest 110: 341-350.

Jacinto, E., R. Loewith, A. Schmidt, S. Lin, M.A. Ruegg, A. Hall, M.N. Hall (2004) Mammalian TOR complex 2 controls the actin cytoskeleton and is rapamycin insensitive. Nat Cell Biol 6: 1122-1128.

Julien, S., I. Puig, E. Caretti, J. Bonaventure, L. Nelles, F. van Roy, C. Dargemont, A.G. de Herreros, A. Bellacosa, L. Larue (2007) Activation of NF-kappaB by Akt upregulates Snail expression and induces epithelium mesenchyme transition. Oncogene 26: 74457456.

Kalluri, R., E.G. Neilson (2003) Epithelial-mesenchymal transition and its implications for fibrosis. J Clin Invest 112: 1776-1784.

Kalluri, R., R.A. Weinberg (2009) The basics of epithelial-mesenchymal transition. J Clin Invest 119: 1420-1428.

Kang, Y., C.R. Chen, J. Massagué (2003) A selfenabling TGF- $\beta$ response coupled to stress signaling: Smad engages stress response factor ATF3 for Id1 repression in epithelial cells. Mol Cell 11: 915-926.
Kishigami, S., Y. Mishina (2005) BMP signaling and early embryonic patterning. Cytokine Growth Factor Rev 16: 265-278.

Klattig, J., C. Englert (2007) The Mullerian duct: recent insights into its development and regression. Sex Dev 1: 271-278.

Klymkowsky, M.W., P. Savagner (2009) Epithelial-mesenchymal transition: a cancer researcher's conceptual friend and foe. Am J Pathol 174: 1588-1593.

Kondo, M., E. Cubillo, K. Tobiume, T. Shirakihara, N. Fukuda, H. Suzuki, K. Shimizu, K. Takehara, A. Cano, M. Saitoh, K. Miyazono (2004) A role for Id in the regulation of TGF$\beta$-induced epithelial-mesenchymal transdifferentiation. Cell Death Differ 11: 10921101.

Kong, W., H. Yang, L. He, J.J. Zhao, D. Coppola, W.S. Dalton, J.Q. Cheng (2008) MicroRNA-155 is regulated by the transforming growth factor- $\beta / S m a d$ pathway and contributes to epithelial cell plasticity by targeting RhoA. Mol Cell Biol 28: 6773-6784.

Lamouille, S., R. Derynck (2007) Cell size and invasion in TGF- $\beta$-induced epithelial to mesenchymal transition is regulated by activation of the mTOR pathway. J Cell Biol 178: 437-451.

Laplante, M., D.M. Sabatini (2009) mTOR signaling at a glance. J Cell Sci 122: 3589-3594.

Larue, L., A. Bellacosa (2005) Epithelial-mesenchymal transition in development and cancer: role of phosphatidylinositol 3-kinase/ AKT pathways. Oncogene 24: 7443-7454.

Lee, M.K., C. Pardoux, M.C. Hall, P.S. Lee, D. Warburton, J. Qing, S.M. Smith, R. Derynck (2007) TGF- $\beta$ activates Erk MAP kinase signaling through direct phosphorylation of ShcA. EMBO J 26: 3957-3967.

$>$ Lee, Y.I., Y.J. Kwon, C.K. Joo (2004) Integrinlinked kinase function is required for transforming growth factor- $\beta$-mediated epithelial to mesenchymal transition. Biochem Biophys Res Commun 316: 997-1001.

Lien, S.C., S. Usami, S. Chien, J.J. Chiu (2006) Phosphatidylinositol 3-kinase/Akt pathway is involved in transforming growth factor$\beta_{1}$-induced phenotypic modulation of 10T1/2 cells to smooth muscle cells. Cell Signal 18: 1270-1278.

Lin, C.C., L.L. Chiang, C.H. Lin, C.H. Shih, Y.T. Liao, M.J. Hsu, B.C. Chen (2007) Transforming growth factor- $\beta_{1}$ stimulates heme oxygenase-1 expression via the PI3K/Akt and NF-kappaB pathways in human lung epithelial cells. Eur J Pharmacol 560: 101-109.

Liu, L., F. Li, J.A. Cardelli, K.A. Martin, J. Blenis, S. Huang (2006) Rapamycin inhibits cell motility by suppression of mTOR-mediated S6K1 and 4E-BP1 pathways. Oncogene 25: 7029-7040.

Liu, P., H. Cheng, T.M. Roberts, J.J. Zhao (2009) Targeting the phosphoinositide 3-kinase pathway in cancer. Nat Rev Drug Discov 8: 627-644. 
Ma, L., M.F. Lu, R.J. Schwartz, J.F. Martin (2005) $\mathrm{Bmp} 2$ is essential for cardiac cushion epithelial-mesenchymal transition and myocardial patterning. Development 132: 5601-5611.

Masszi, A., A. Kapus (2011) Smaddening complexity: The role of Smad3 in epithelial-myofibroblast transition. Cells Tissues Organs 193: 41-52.

McDonald, P.C., A.B. Fielding, S. Dedhar (2008) Integrin-linked kinase - essential roles in physiology and cancer biology. J Cell Sci 121: 3121-3132.

Meindl-Beinker, N.M., S. Dooley (2008) Transforming growth factor- $\beta$ and hepatocyte transdifferentiation in liver fibrogenesis. J Gastroenterol Hepatol 23 (suppl 1): S122S127.

Mercado-Pimentel, M.E., R.B. Runyan (2007) Multiple transforming growth factor- $\beta$ isoforms and receptors function during epithelial-mesenchymal cell transformation in the embryonic heart. Cells Tissues Organs 185: 146-156.

Miettinen, P.J., R. Ebner, A.R. Lopez, R. Derynck (1994) TGF- $\beta$ induced transdifferentiation of mammary epithelial cells to mesenchymal cells: involvement of type I receptors. J Cell Biol 127: 2021-2036.

-Miyazono, K (2009) Transforming growth factor- $\beta$ signaling in epithelial-mesenchymal transition and progression of cancer. Proc Jpn Acad Ser B Phys Biol Sci 85: 314-323.

-Moreno-Bueno, G., F. Portillo, A. Cano (2008) Transcriptional regulation of cell polarity in EMT and cancer. Oncogene 27: 6958-6969.

-Moustakas, A., C.H. Heldin (2005) Non-Smad TGF- $\beta$ signals. J Cell Sci 118: 3573-3584.

Moustakas, A., C.H. Heldin (2007) Signaling networks guiding epithelial-mesenchymal transitions during embryogenesis and cancer progression. Cancer Sci 98: 1512-1520.

- Nakajima, Y., T. Yamagishi, S. Hokari, H. Nakamura (2000) Mechanisms involved in valvuloseptal endocardial cushion formation in early cardiogenesis: roles of transforming growth factor (TGF) $\beta$ and bone morphogenetic protein (BMP). Anat Rec 258: 119-127.

-Nawshad, A., D. LaGamba, E.D. Hay (2004) Transforming growth factor- $\beta$ (TGF- $\beta$ ) signaling in palatal growth, apoptosis and epithelial mesenchymal transformation (EMT). Arch Oral Biol 49: 675-689.

-Nguyen, D.X., J. Massagué (2007) Genetic determinants of cancer metastasis. Nat Rev Genet 8: 341-352.

-Oft, M., K.H. Heider, H. Beug (1998) TGF- $\beta$ signaling is necessary for carcinoma cell invasiveness and metastasis. Curr Biol 8: 12431252.

Dzdamar, B., R. Bose, M. Barrios-Rodiles, H.R. Wang, Y. Zhang, J.L. Wrana (2005) Regulation of the polarity protein Par6 by TGF- $\beta$ receptors controls epithelial cell plasticity. Science 307: 1603-1609.

Padua, D., J. Massagué (2009) Roles of TGF- $\beta$ in metastasis. Cell Res 19: 89-102.
- Peinado, H., D. Olmeda, A. Cano (2007) Snail, Zeb and bHLH factors in tumour progression: an alliance against the epithelial phenotype? Nat Rev Cancer 7: 415-428.

Pellegrin, S., H. Mellor (2007) Actin stress fibres. J Cell Sci 120: 3491-3499.

Pelton, R.W., B.L. Hogan, D.A. Miller, H.L. Moses (1990) Differential expression of genes encoding TGFs $\beta_{1}, \beta_{2}$, and $\beta_{3}$ during murine palate formation. Dev Biol 141: 456-460.

Perez-Moreno, M.A., A. Locascio, I. Rodrigo, G. Dhondt, F. Portillo, M.A. Nieto, A. Cano (2001) A new role for E12/E47 in the repression of E-cadherin expression and epithelialmesenchymal transitions. J Biol Chem 276: 27424-27431.

Perk, J., A. Iavarone, R. Benezra (2005) Id family of helix-loop-helix proteins in cancer. Nat Rev Cancer 5: 603-614.

Piek, E., A. Moustakas, A. Kurisaki, C.H. Heldin, P. ten Dijke (1999) TGF- $\beta$ type I receptor/ ALK-5 and Smad proteins mediate epithelial to mesenchymal transdifferentiation in NMuMG breast epithelial cells. J Cell Sci 112: 4557-4568.

Pon, Y.L., H.Y. Zhou, A.N. Cheung, H.Y. Ngan, A.S. Wong (2008) p70 S6 kinase promotes epithelial to mesenchymal transition through snail induction in ovarian cancer cells. Cancer Res 68: 6524-6532.

Portella, G., S.A. Cumming, J. Liddell, W. Cui, H. Ireland, R.J. Akhurst, A. Balmain (1998) Transforming growth factor- $\beta$ is essential for spindle cell conversion of mouse skin carcinoma in vivo: implications for tumor invasion. Cell Growth Differ 9: 393-404.

Qiao, M., J.D. Iglehart, A.B. Pardee (2007) Metastatic potential of $21 \mathrm{~T}$ human breast cancer cells depends on Akt/protein kinase B activation. Cancer Res 67: 5293-5299.

Robert, F., J. Pelletier (2009) Translation initiation: a critical signaling node in cancer. Expert Opin Ther Targets 13: 1279-1293.

-Rodriguez-Barbero, A., F. Dorado, S. Velasco, A. Pandiella, B. Banas, J.M. Lopez-Novoa (2006) TGF- $\beta_{1}$ induces COX-2 expression and PGE2 synthesis through MAPK and PI3K pathways in human mesangial cells. Kidney Int 70: 901-909.

Ruzinova, M.B., R. Benezra (2003) Id proteins in development, cell cycle and cancer. Trends Cell Biol 13: 410-418.

Santibanez, J.F. (2006) JNK mediates TGF- $\beta_{1^{-}}$ induced epithelial mesenchymal transdifferentiation of mouse transformed keratinocytes. FEBS Lett 580: 5385-5391.

Sarbassov, D.D., S.M. Ali, D.H. Kim, D.A. Guertin, R.R. Latek, H. Erdjument-Bromage, P. Tempst, D.M. Sabatini (2004) Rictor, a novel binding partner of mTOR, defines a rapamycin-insensitive and raptor-independent pathway that regulates the cytoskeleton. Curr Biol 14: 1296-1302.
Sarbassov, D.D., D.A. Guertin, S.M. Ali, D.M. Sabatini (2005) Phosphorylation and regulation of Akt/PKB by the rictor-mTOR complex. Science 307: 1098-1101

Schmidt, C.R., Y.J. Gi, T.A. Patel, R.J. Coffey, R.D. Beauchamp, A.S. Pearson (2005) E-cadherin is regulated by the transcriptional repressor SLUG during Ras-mediated transformation of intestinal epithelial cells. Surgery 138: 306-312.

-Schnaper, H.W., T. Hayashida, S.C. Hubchak, A.C. Poncelet (2003) TGF- $\beta$ signal transduction and mesangial cell fibrogenesis. Am J Physiol Renal Physiol 284: F243-F252.

$\checkmark$ Shi, Y., J. Massagué (2003) Mechanisms of TGF$\beta$ signaling from cell membrane to the nucleus. Cell 113: 685-700.

-Shirakihara, T., M. Saitoh, K. Miyazono (2007) Differential regulation of epithelial and mesenchymal markers by deltaEF1 proteins in epithelial mesenchymal transition induced by TGF- $\beta$. Mol Biol Cell 18: 3533-3544.

Sorrentino, A., N. Thakur, S. Grimsby, A. Marcusson, V. von Bulow, N. Schuster, S. Zhang, C.H. Heldin, M. Landstrom (2008) The type I TGF- $\beta$ receptor engages TRAF6 to activate TAK1 in a receptor kinase-independent manner. Nat Cell Biol 10: 1199-1207.

Tavares, A.L., M.E. Mercado-Pimentel, R.B. Runyan, G.T. Kitten (2006) TGF- $\beta$-mediated RhoA expression is necessary for epithelialmesenchymal transition in the embryonic chick heart. Dev Dyn 235: 1589-1598.

Theriault, B.L., T.G. Shepherd, M.L. Mujoomdar, M.W. Nachtigal (2007) BMP4 induces EMT and Rho GTPase activation in human ovarian cancer cells. Carcinogenesis 28: 1153-1162.

Thiery, J.P (2003) Epithelial-mesenchymal transitions in development and pathologies. Curr Opin Cell Biol 15: 740-746.

-Thiery, J.P., H. Acloque, R.Y. Huang, M.A. Nieto (2009) Epithelial-mesenchymal transitions in development and disease. Cell 139: 871890.

Thiery, J.P., J.P. Sleeman (2006) Complex networks orchestrate epithelial-mesenchymal transitions. Nat Rev Mol Cell Biol 7: 131-142.

Thuault, S., U. Valcourt, M. Petersen, G. Manfioletti, C.H. Heldin, A. Moustakas (2006) Transforming growth factor- $\beta$ employs HMGA2 to elicit epithelial-mesenchymal transition. J Cell Biol 174: 175-183.

Uttamsingh, S., X. Bao, K.T. Nguyen, M. Bhanot, J. Gong, J.L. Chan, F. Liu, T.T. Chu, L.H. Wang (2008) Synergistic effect between EGF and TGF- $\beta_{1}$ in inducing oncogenic properties of intestinal epithelial cells. Oncogene 27: 2626-2634.

Valcourt, U., M. Kowanetz, H. Niimi, C.H. Heldin, A. Moustakas (2005) TGF- $\beta$ and the Smad signaling pathway support transcriptomic reprogramming during epithelialmesenchymal cell transition. Mol Biol Cell 16: 1987-2002. 
-Vardouli, L., A. Moustakas, C. Stournaras (2005) LIM-kinase 2 and cofilin phosphorylation mediate actin cytoskeleton reorganization induced by transforming growth factor- $\beta$. J Biol Chem 280: 11448-11457.

Vincent, T., E.P. Neve, J.R. Johnson, A. Kukalev, F. Rojo, J. Albanell, K. Pietras, I. Virtanen, L. Philipson, P.L. Leopold, R.G. Crystal, A.G. de Herreros, A. Moustakas, R.F. Pettersson, J. Fuxe (2009) A SNAIL1-SMAD3/4 transcriptional repressor complex promotes TGF- $\beta$ mediated epithelial-mesenchymal transition. Nat Cell Biol 11: 943-950.

-Willis, B.C., Z. Borok (2007) TGF- $\beta$-induced EMT: mechanisms and implications for fibrotic lung disease. Am J Physiol Lung Cell Mol Physiol 293: L525-L534.

-Wu, L., R. Derynck (2009) Essential role of TGF$\beta$ signaling in glucose-induced cell hypertrophy. Dev Cell 17: 35-48.

Xie, L., B.K. Law, A.M. Chytil, K.A. Brown, M.E. Aakre, H.L. Moses (2004) Activation of the Erk pathway is required for TGF- $\beta_{1}$-induced EMT in vitro. Neoplasia 6: 603-610.

Xu, J., S. Lamouille, R. Derynck (2009) TGF- $\beta$ induced epithelial to mesenchymal transition. Cell Res 19: 156-172.
Yamashita, M., K. Fatyol, C. Jin, X. Wang, Z. Liu, Y.E. Zhang (2008) TRAF6 mediates Smadindependent activation of JNK and p38 by TGF- $\beta$. Mol Cell 31: 918-924.

-Yang, J., S.A. Mani, J.L. Donaher, S. Ramaswamy, R.A. Itzykson, C. Come, P. Savagner, I. Gitelman, A. Richardson, R.A. Weinberg (2004) Twist, a master regulator of morphogenesis, plays an essential role in tumor metastasis. Cell 117: 927-939.

Yeh, Y.Y., C.C. Chiao, W.Y. Kuo, Y.C. Hsiao, Y.J. Chen, Y.Y. Wei, T.H. Lai, Y.C. Fong, C.H. Tang (2008) TGF- $\beta_{1}$ increases motility and $\alpha v \beta_{3}$ integrin up-regulation via PI3K, Akt and NF-kappaB-dependent pathway in human chondrosarcoma cells. Biochem Pharmacol 75: 1292-1301.

Yi, J.Y., I. Shin, C.L. Arteaga (2005) Type I transforming growth factor- $\beta$ receptor binds to and activates phosphatidylinositol 3-kinase. J Biol Chem 280: 10870-10876.

Yilmaz, M., G. Christofori (2009) EMT, the cytoskeleton, and cancer cell invasion. Cancer Metastasis Rev 28: 15-33.

Yu, L., M.C. Hebert, Y.E. Zhang (2002) TGF- $\beta$ receptor-activated p38 MAP kinase mediates Smad-independent TGF- $\beta$ responses. EMBO J 21: 3749-3759.
Zavadil, J., E.P. Böttinger (2005) TGF- $\beta$ and epithelial-to-mesenchymal transitions. Oncogene 24: 5764-5774.

Zeisberg, E.M., O. Tarnavski, M. Zeisberg, A.L. Dorfman, J.R. McMullen, E. Gustafsson, A. Chandraker, X. Yuan, W.T. Pu, A.B. Roberts, E.G. Neilson, M.H. Sayegh, S. Izumo, R. Kalluri (2007) Endothelial-to-mesenchymal transition contributes to cardiac fibrosis. Nat Med 13: 952-961.

Zeisberg, M., J. Hanai, H. Sugimoto, T. Mammoto, D. Charytan, F. Strutz, R. Kalluri (2003) BMP-7 counteracts TGF- $\beta_{1}$-induced epithelial-to-mesenchymal transition and reverses chronic renal injury. Nat Med 9: 964-968.

Zeisberg, M., E.G. Neilson (2009) Biomarkers for epithelial-mesenchymal transitions. J Clin Invest 119: 1429-1437.

Zeisberg, M., A.A. Shah, R. Kalluri (2005) Bone morphogenic protein-7 induces mesenchymal to epithelial transition in adult renal fibroblasts and facilitates regeneration of injured kidney. J Biol Chem 280: 8094-8100.

Zhou, B.P., J. Deng, W. Xia, J. Xu, Y.M. Li, M. Gunduz, M.C. Hung (2004) Dual regulation of Snail by GSK-3beta-mediated phosphorylation in control of epithelial-mesenchymal transition. Nat Cell Biol 6: 931-940. 